\title{
PHYSICAL PRINCIPLES IN TECHNICAL EDUCATION
}

\author{
Jan Novotny \\ J. E. Purkyne University in Usti nad Labem, Czech Republic \\ novotny@fvtm.ujep.cz
}

\begin{abstract}
This contribution informs about the way to eliminate barrier disinterest of studying concern in the technical field by means of organizing actions, which have put the basic goal - to increase interest of students in technical education. Pedagogical action impress in a frame of physical principles is used in laboratory for phenomena at the interface demonstration and testing its possibilities of using in the teaching of physics at technical universities. Currently, a lot of technically-oriented universities are fighting with the outflow of students and with barrier disinterest of studying concern in the technical field. The source of such a phenomenon is little awareness of students of the technical colleges and universities. It shows how to use the pedagogical effect practically in preparing students for the basic technology. It shows how to increase activity and productivity of students by the right focus on the problem. Research of students cooperation with a teacher in terms of project in technical education is not only nonverbal empirical research, but at the same time shows how the technical teaching process evolves in technically oriented subjects of school educational programmes. Training for technical cooperated projects in relation student-teacher should become part of teaching, if possible, as students cannot be taught in creativity in an isolated manner. Technical and natural subjects are the subjects much suitable for incorporating assignments developing such abilities. Training in technical projects is a very difficult activity, which will only be managed by a teacher, who himself/herself is not only creative, but also prepared methodically for managing and guiding such activities. Therefore, it is necessary to lead the students to creativity, train them to be creative, and provide them with such methodical training. In this article a method is described, how to manage cooperation with students, which leads to deeper understanding of technical problems.
\end{abstract}

Keywords: technical and natural science, technical education.

\section{Introduction}

Our society underwent many social-economic changes in the past years - changes in ownership relations, working and family environment, as well as changes in the system of social values, which brought many people to situations requiring a different way of thinking and different procedures than those common before. Changes in the work style in our schools occur with the change of our social environment [1].

Such method, described in the article, is not a statistic research supported activity. It is based on empirical assessment of given situation. This situation, where the student is cooperating with the teacher on preparing of physical aids to understand a problem, should be a way to solve the problem how to teach topics like this.

Currently a lot of technically-oriented universities are fighting with outflow of students and with barrier disinterest of studying concern in the technical field. The source of such a phenomenon is little awareness of pupils of the technical colleges and universities. A very good way to eliminate this barrier is to try to do physical teaching as entertainment at the Faculty of Mechanical Engineering of Jan Evangelista Purkyně University in Ústí nad Labem, Czech Republic. These actions have put some basic goals [2]:

- improve awareness of technical subjects and technology,

- improve and increase mutual awareness of belonging to the university, faculty and regional education,

- enable students to make attractive and entertaining physical experiments and experiments from other sectors of technical education,

- provide students themselves to inspiration and self-education.

\section{Moment of inertia}

Moment of inertia is a substance that needs to be thoroughly discussed and studied already during the secondary school years. A student, who is going to study at high school of technical nature or to study natural sciences, has a great chance of meeting this kind of problem again. It, therefore, depends on how the substance is discussed. Most of us know from our own experience that, if the theoretical 
curriculum is sufficiently grounded in practical demonstration or laboratory measurement, the effect of remembering the subject is considerably higher.

Last but not the least, the practical verification of the curriculum has a significant influence on the understanding of the whole issue.

The described laboratory problem was compiled for teaching the thematic unit Dynamics of Rotational Movement at the Faculty of Mechanical Engineering of the Jan Evangelista Purkyně University. The laboratory role was created as a complete unit. This means from the actual theoretical assembly of the task to the construction and manufacture of the measuring instrument. This device was developed within the course of the Workshop Physical Practice course. Students have the opportunity to thoroughly examine the rules of the subject matter on the device they produced themselves.

\section{The "DRM" device and its design}

The name of the device was formed by the abbreviated words Dynamics of Rotational Movement. A complete assembled instrument ready for measurement is shown in Fig. 1[3].

a)

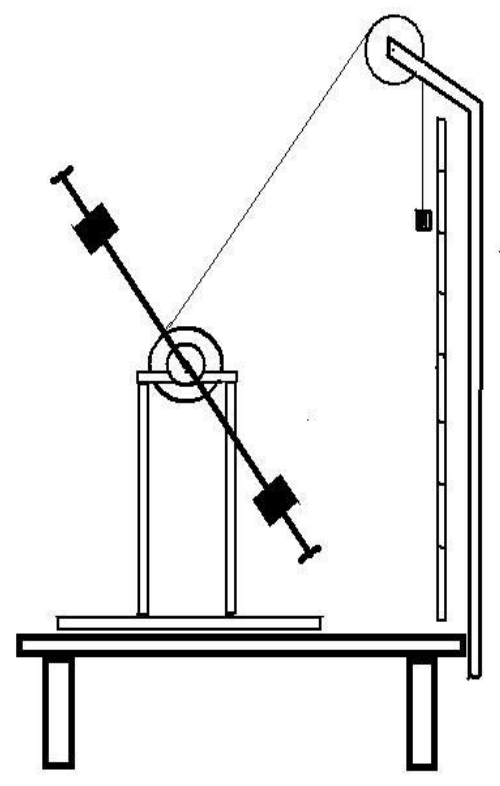

b)

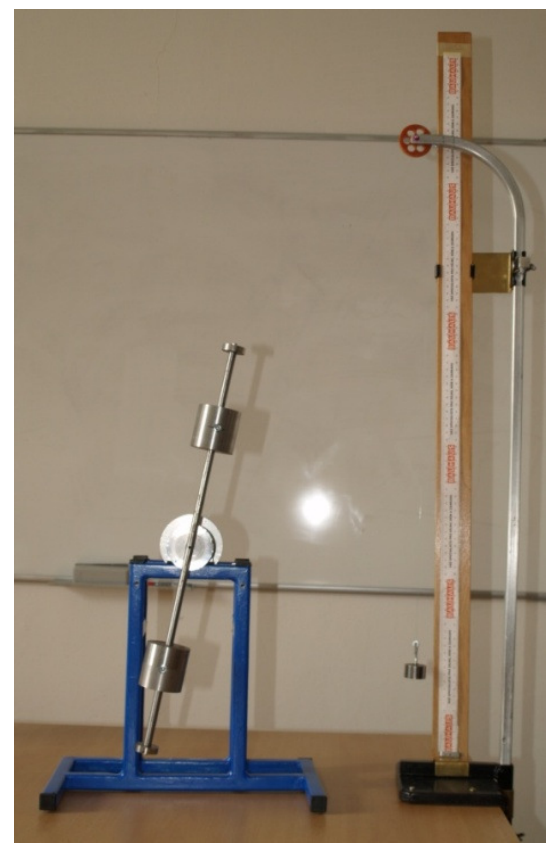

Fig. 1. DRM ready-to-use assembled: $a$ - drawing; $b$ - real instrument [3]

\section{Theory of measurement, determination of the final value $J$}

The weight has a potential energy in the upper position, which, when the weight decreases, changes to the kinetic energy of the progressive movement of the $1 / 2 m v^{2}$ and kinetic energy of the rotor $1 / 2 \mathrm{~J} \omega^{2}$.

At the same time, part of the mechanical energy is lost; because it is converted to heat by the action of the braking resistive forces $F_{b}$.

This loss of energy can be expressed as the work of braking forces $F_{b}$ along the line $h_{1}-h_{0}$.

Thus, the energy $F_{b} \cdot\left(h_{1}-h_{0}\right)$ was transformed into heat.

The kinetic energy of the weight is very small compared to the kinetic energy of the rotor

$1 / 2 m v^{2}<<1 / 2 J \omega^{2}$, so we can neglect it [3].

Under these assumptions we will use the Energy Conservation Act. For the weight decline phase the following equation applies:

$$
m g \cdot\left(h_{1}-h_{0}\right)=\frac{1}{2} \cdot J \omega^{2}+F_{b}\left(h_{1}-h_{0}\right) .
$$


At the moment the weight is at the bottom, all mechanical energy of the system is in the rotating rotor. The rotor inertia continues to rotate, the fibre winds to the rotor, the weight moves up. It stops at the height of $h_{2}\left(h_{2}<h_{1}\right)$.

The kinetic energy of the rotor $1 / 2 J \omega^{2}$ has been converted to the potential energy of the weights $m g \cdot\left(h_{2}-h_{0}\right)$ and heat $F_{b} \cdot\left(h_{2}-h_{0}\right)$ [3].

For the step of climbing weights $\mathrm{m}$ up to $\mathrm{h} 2$ the following equation applies:

$$
\frac{1}{2} \cdot J \omega^{2}=m g \cdot\left(h_{2}-h_{0}\right)+F_{b}\left(h_{2}-h_{0}\right) .
$$

By solving the system of equations (1), (2) we express the braking force size:

$$
F_{b}=m g \cdot \frac{h_{1}-h_{2}}{h_{1}+h_{2}-2 h_{0}} .
$$

The weight decreases with evenly accelerated motion

$$
v=a t
$$

and its speed is as large as the peripheral velocity of the winch pulley

$$
v=\omega r .
$$

The maximum speed is reached at time $\mathrm{t}$, when the weight runs a lane $\left(h_{1}-h_{0}\right)$. For the lane of equally accelerated descent movement we can use the following equation:

$$
\left(h_{1}-h_{0}\right)=\frac{1}{2} a t^{2} \text {. }
$$

From equation (4) we put acceleration and from equation (5) we will put velocity substitution in equation (6).

We obtain:

$$
\omega=\frac{2\left(h_{1}-h_{0}\right)}{r t} .
$$

If we put $F_{b}$ from (3) and $\omega$ from (7) into equation (1) and adjust, we get the resulting relation for calculating the moment of inertia $J$. It is necessary to set correctly the measured values and to quantify [3].

$$
J=m g \frac{h_{2}-h_{0}}{\left(h_{1}-h_{0}\right) \cdot\left(h_{1}+h_{2}-2 h_{0}\right)} \cdot r^{2} t^{2} .
$$

\section{Results and discussion}

1. The experiment is effective enough to attract students. This is acceptable to practically all students of higher education institutions, such as technical ones.

2. Physical content is well-communicated and therefore easily enlisted in teaching, with the students uniquely leading to a better understanding of the subject.

3. The use of teaching methods, in addition to classical theoretical analysis of the curriculum and the practical verification, leads students to better acquiring of the knowledge from the given subject.

4. Such events ensure students' satisfaction. Students themselves gain this approach as a positive attitude to study technical subjects.

5. Students, who themselves carry out the operations or experiments that until now were regarded as very difficult and completely impossible to understand, desire to further study technical subjects. These subjects often lead to the educator's satisfactory outcome effort. In active pupils participation in the event, where they can test themselves by demanding experiments and then penetrate into the matter, students will gain a positive relationship to a given subject matter and often clearly decide on the suitability of the chosen technical fields [4]. 
6. The author was talking to several colleagues from other countries, from Visegrad Region, where there is a similar situation. After cooperation in the discussion it could be said that the way of cooperation with students to solve problems increases understanding of technical and natural curriculum.

7. Content of such courses gives us an opportunity to motivate students in relation to technical subjects. It is necessary to obtain a broader view and understand the general dynamics of the relationship between man and the natural sciences, or between man and the technology.

\section{Conclusions}

The present process of education can be regarded as a very complex system, which takes place in terms of interaction and cross-objective and subjective factors. Personal potential and actual students and teachers are changing.

This potential is beginning to adapt to the present social conditions, and future of human society. Change of living conditions and lifestyles affects the transformation of Czech education, which is currently undergoing some changes, in which the transformations from conventional to traditional forms of teaching are preferred. The most effective in the process of student's personality developing and value orientation can be organizing of educational events, which are still in our schools under-used. Absence of such actions may be due to insufficient experience with these methods or little courage of teachers to start with something new and different. In addition to this fact, certainly contributes the fact that the organization of such events is timeconsuming. Last but not the least, note that the method of teaching, and hence the choice of the teaching methods and forms of work, affect the school itself - its facilities and flexibility. Now this situation should at least partially solve the cooperation of all school stages in the region.

The event is organized for the target group of students at the university in order to become familiar with the fun and fascinating form of teaching physics and other technical subjects. Students have the opportunity to penetrate in the secrets of material testing, production of prototypes of three-dimensional printing, plastic, etc. The greatest interest, however, enjoys the event called Physics experiments - physics fun. Pupils are able to see and try these interesting and often surprising principles and experiments in the field of electrical engineering, mechanics, microwave technology and other physical disciplines. Because the results are presented in a fun and engaging manner, it gives the students a natural interest in technology and engineering fields.

\section{References}

[1] Novotny J. Technical education and conditions of technical education as a means to develop creativity. In Journal of Technology and Information Education, Ročník 7; Číslo 1, Olomouc: UP, 2015, pp. 100-104.

[2] Zukerstein J. Aktivizační metody a jejich význam (Activation methods and their significance). In Modernizace výuky v technicky orientovaných oborech a předmětech. Olomouc, UP 1999, pp. 135-137. (In Czech)

[3] Novotny J. Měření momentu setrvačnosti (Measure moment of inertia). In. Matematika - Fyzika Informatika. Olomouc, 2011, číslo 5, pp. 283-288. (In Czech)

[4] Novotny J. Technical and natural sciences teaching at engineering faculty of FPTM UJEP, Engineering for Rural Development, 2016 Vol. 15, Latvia, , 2016 pp. 16-20. 